Commentary

\title{
Science Journalism and Pandemic Uncertainty
}

\author{
Sharon Dunwoody \\ School of Journalism and Mass Communication, University of Wisconsin-Madison, Madison, WI 53706, USA; \\ E-Mail: dunwoody@wisc.edu
}

Submitted: 1 May 2020 | Accepted: 5 May 2020 | Published: 26 June 2020

\begin{abstract}
Novel risks generate copious amounts of uncertainty, which in turn can confuse and mislead publics. This commentary explores those issues through the lens of information seeking and processing, with a focus on social media and the potential effectiveness of science journalism.
\end{abstract}

\section{Keywords}

Covid-19; information processing; information seeking; science journalism; social media

\section{Issue}

This commentary is part of the issue "Health and Science Controversies in the Digital World: News, Mis/Disinformation and Public Engagement" edited by An Nguyen (Bournemouth University, UK) and Daniel Catalan (University Carlos III of Madrid, Spain).

(C) 2020 by the author; licensee Cogitatio (Lisbon, Portugal). This article is licensed under a Creative Commons Attribution 4.0 International License (CC BY).

As I write this commentary, Covid-19 continues its relentless march across nations, neighborhoods and families. While stringent control measures are beginning to weaken the coronavirus's foothold in some parts of the world, scientists continue to scramble to understand this novel threat and to develop ways to intervene.

What fertile ground for perceptions of uncertainty! Both communication scholars (see, for example, Krause, Freiling, Beets, \& Brossard, 2020) and savvy science journalists such as The Atlantic's Ed Yong (2020) are turning their attention to uncertainty as both a facilitator of and a roadblock to functional use of Covid-19 information. Front and center in these explorations is social media, where information, misinformation and disinformation all flourish. In this brief commentary, I will reflect on the ways in which social media are affecting uncertainty perceptions about the pandemic, as well as on ways in which journalists can contribute to a more accurate reckoning in this crisis.

First, a quick look at uncertainty itself. I like to think of uncertainty as an awareness of what we do not know. Where that uncertainty resides and how it is articulated varies, according to Kahneman and Tversky (1982), who divide uncertainty into two domains: external and internal. External uncertainty captures the limitations of ev- idence in the external world, articulated in journal articles, in TED talks by experts, in conversations with our doctors. Internal uncertainty, on the other hand, is reflected in our personal judgments about the risks around us. Those perceptions may be influenced by an understanding of what we do not know (uncertainty), as well as, inadvertently, by phenomena of which we are not aware (ignorance).

Kampourakis and McCain advance this understanding of uncertainty by themselves employing two dimensions. In their recent book, Uncertainty: How It Makes Science Advance (Kampourakis \& McCain, 2019), they distinguish between epistemic and psychological certainty. Epistemic certainty requires the presence of evidence that is "so strong that it makes it impossible that you could be wrong" (Kampourakis \& McCain, 2019, p. 7, italics in original), while psychological certainty reflects "how strongly we believe something" (Kampourakis \& McCain, 2019, p. 6). Since science can never muster enough evidence to enable epistemic certainty, they argue, we must live with personal, psychological uncertainty and better understand the factors that influence it. Kahneman and Tversky, I believe, would agree.

Those factors include the extent to which a person is willing to seek out and then process information ef- 
fortfully, as systematic processing has long been associated with more accurate risk perceptions. Alas, we humans have never been good at this. We typically engage in rather superficial information seeking and processing, relying on small dollops of information from a modest cadre of sources (sometimes even one source will do!) for even the most important decisions. And when it comes to judgments of the credibility of evidence about a risk, that means we are far more likely to judge the credibility of information channels rather than engaging in the more effortful process of evaluating information sources. Assuming that stories in The Guardian or on Fox News are trustworthy saves individuals the time needed to evaluate the credibility of each of the many sources that they encounter in the stories offered by those channels.

German psychologist Gerd Gigerenzer maintains that relying on such "rules of thumb" to make rapid decisions can be quite functional, as that reliance is often based on years of experience with the world around us (see, for example, Gigerenzer, 2015). I get that. But how can we extract reliable information when we encounter a novel threat and when our information environment is awash in contradictory information? That, in a nutshell, is the situation we face with the Covid-19 pandemic.

Uncertainty in the face of health threats scares people, and novel threats such as Covid-19 maximize the perception of uncertainty in several ways. For one thing, as of this writing we truly know little about this virus, whose official name, conferred only in February 2020, is "severe acute respiratory syndrome coronavirus 2 (SARS-CoV-2)" (Joseph, 2020). The illness itself is called Covid-19, which stands for "coronavirus disease 2019"; I will use that latter term henceforth. Scientists are continually unearthing information about this coronavirus, but external/epistemic uncertainty remains extremely high. Ed Yong, in his April 29 article, notes that much about the pandemic remains "maddeningly unclear" (Yong, 2020). Even systematic information seekers and processors, as rare as they are, are hard-pressed to learn enough about the virus and its impact to feel even modestly efficacious.

Another uncertainty generator is the wide variance in policy responses to the spread of Covid-19 both across countries and within them. While one country remains virtually locked down, another restricts only the elderly and infirm. While one city extends orders to stay home, another opens restaurants and hair salons. Country leaders uniformly express caution, but their messaging reveals wildly varying levels of coping with the pandemic.

Finally, the internet and social media have played a major role in exacerbating uncertainty perceptions. Many individuals worldwide now use social media as their primary-perhaps their only-news channel, although surveys in the US indicate that Americans regard social media as less trustworthy deliverers of news than more traditional channels. A recent survey of US adults about their pandemic perceptions found high levels of distrust of social media channels; for example, nearly
$50 \%$ of respondents said that they distrust Facebook as a source of Covid-19 information (Ballew et al., 2020). The most trusted sources of information emerging from that survey, not surprisingly, were personal physicians and infectious disease experts.

Reliance on less trustworthy channels, such as stories posted on one's Facebook feed, seems to make no sense. But scholars who study channel use have found that, given two factors influencing channel choices-the likelihood of finding relevant information and the 'cost' of accessing a channel-the latter often trumps the former. For example, although we prefer to interact with medical professionals when we need health information, we rarely do so. Instead, we 'make do' with mediated channels and the internet because the cost-both in terms of time and money-is much less.

However, reliance on less trustworthy channels opens the door to misinformation (information that is inadvertently inaccurate) and disinformation (information that is deliberately inaccurate) about the pandemic. In mid-April, UN Secretary-General António Guterres warned of a "global misinfo-demic" around the world prompted by "falsehoods" on the airwaves and "wild conspiracy theories" on the internet (United Nations, 2020). We know that false messages are shared more frequently online than are accurate ones, thanks to their high levels of emotional content and vividness (Vosoughi, Roy, \& Aral, 2018). And we also know that the presence of conflicting messages in one's social feed makes it more difficult for an individual to distinguish the credible from the non-credible (Karduni et al., 2018). That means this avalanche of inconsistent, sometimes misleading information can dramatically increase perceptions of uncertainty.

We are desperate to reduce uncertainty in times like this in order to select a path through an imminent risk, and communication theories suggest a number of uncertainty reduction drivers that influence our seeking and use of information. For example, Kim Witte's Extended Parallel Process Model (Witte, 1994) predicts that fear combined with a sense of helplessness can lead a person to try to bury a problem by ignoring it. In such situations, individuals may avoid information altogether and engage in 'business as usual.'

Another driver is our tendency to perceive ourselves as more immune to a risk than are others. Multiple studies over the years have found that we tend to downplay our likelihood of harm from risks of all kinds. When asked, we report that 'others' are far more likely to be harmed than are we. Dubbed 'optimism bias' (Weinstein, 1989), this sense of personal invulnerability can lead a person to readily ingest even conflicting information about a risk but then to set aside the information because it is 'not about me.' A recent survey supporting this "me/them" differential pattern found that, while $62 \%$ of Americans thought the coronavirus will do a "great deal" of harm to people in the country, only $25 \%$ felt that the virus would harm them personally (Ballew et al., 2020). 
A third important driver is to limit one's exposure to conflicting information by employing that channel heuristic, defaulting to the information channels we deem credible. That means that individuals, although they may access a similar volume of messages about the pandemic, are not encountering the same messages. Beliefs about what is true begin to vary in dysfunctional ways at an aggregate level, leading to a challenging situation: Individuals may report relatively high levels of Covid-19 knowledge but may, in fact, 'know' wildly dissimilar things.

Intensifying this channel heuristic is the early politicization of the Covid-19 pandemic itself. Nisbet and colleagues have tracked this process in other science issues and found that information about a science issue is usually driven largely by the scientific community in initial stages but then is gradually dominated by political sources (Nisbet \& Fahy, 2015). Over time-think climate change, evolution, vaccines and autism - the issue becomes firmly embedded in ideological discourse, encouraging use of information channels that help support those ideological viewpoints. While issue politicization in science is, unfortunately, not unusual, the speed with which the coronavirus pandemic became politicized has been breathtaking. Political figures and ideological groups began building partisan narratives about the risk immediately, competing directly with science narratives that sought to focus on evidence.

So how can journalists negotiate these volatile waters in ways that deliver information that can help readers maintain an accurate sense of pandemic uncertainty? For one thing, science journalists continue to privilege scientific sources and, although trust in all occupations has declined in the US over the decades, scientists and physicians remain high in the credibility line-up. Most of us are more likely to believe what scientists tell us about a scientific issue than what we glean from other types of sources.

For another thing, a large contingent of news consumers continues to rely on mediated channels for information, where journalists gather and evaluate information before packaging it for public consumption. This gives specialized journalists an opportunity to maintain some control over the Covid-19 narratives. The quality of science journalism stories generally has increased over the years, and efforts to cope with declining revenue and competition from social media has sparked an increase in analytical stories, which concentrate on context and promoting understanding. The piece by journalist Ed Yong (2020) is an excellent example of that trend. Nisbet and Fahy (2015) devote an entire article to a discussion of "knowledge-based" journalism as a "fix" for the volatile information world journalism now inhabits.

Finally, a dramatic increase in fact-checking among media organizations around the world gives audiences the opportunity to access almost immediate comparisons between claims and evidence for or against those assertions. Krause et al. (2020) warn that issues of trust can attenuate the power of fact-checking, but journalists' willingness to analyze the validity of truth claims is a welcome step.

\section{Conflict of Interests}

The author declares no conflict of interests.

\section{References}

Ballew, M., Bergquist, P., Goldberg, M., Gustafson, A., Kotcher, J., Marlon, J., . . . Leiserowitz, A. (2020). American public responses to COVID-19, April 2020. New Haven, CT: Yale Program on Climate Change Communication. Retrieved from https:// climatecommunication.yale.edu/publications/ american-public-responses-to-Covid-19-april2020/5

Gigerenzer, G. (2015). Risk savvy: How to make good decisions. New York, NY: Penguin.

Joseph, A. (2020) Disease caused by the novel coronavirus officially has a name: Covid-19. STAT. Retrieved from https://www.statnews.com/2020/ 02/11/disease-caused-by-the-novel-coronavirushas-name-covid-19

Kahneman, D., \& Tversky, A. (1982). Variants of uncertainty. Cognition, 11(2), 143-157.

Kampourakis, K., \& McCain, K. (2019). Uncertainty: How it makes science advance. New York, NY: Oxford University Press.

Karduni, A., Wesslen, R., Santhanam, S., Cho, I., Volkova, S., Arendt, D., . . . Dou, W. (2018). Can you verify this? Studying uncertainty and decision-making about misinformation using visual analytics. Proceedings of the Twelfth International AAAI Conference on Web and Social Media. Palo Alto, CA: AAAI Press. Retrieved from https://www.aaai.org/ocs/index.php/ ICWSM/ICWSM18/paper/viewPaper/17853

Krause, N. M., Freiling, I., Beets, B., \& Brossard, D. (2020). Fact-checking as risk communication: The multilayered risk of misinformation in times of COVID-19. Journal of Risk Research. Advance online publication. https://doi.org/10.1080/13669877.2020.1756385

Nisbet, M. C., \& Fahy, D. (2015). The need for knowledgebased journalism in politicized science debates. The ANNALS of the American Academy of Political and Social Science, 658(1), 223-234.

United Nations. (2020). Hatred going viral in "dangerous epidemic of misinformation" during COVID-19 pandemic. UN News. Retrieved from https://news. un.org/en/story/2020/04/1061682

Vosoughi, S., Roy, D., \& Aral, S. (2018). The spread of true and false news online. Science, 359(6380), 1146-1151.

Weinstein, N. D. (1989). Optimistic biases about personal risks. Science, 246(4935), 1232-1234.

Witte, K. (1994). Fear control and danger control: A test of the extended parallel process model (EPPM). Communications Monographs, 61(2), 113-134. 
Yong, E. (2020, April 29). Why the coronavirus is so confusing. The Atlantic. Retrieved from https://www. theatlantic.com/health/archive/2020/04/pandemicconfusing-uncertainty/610819

\section{About the Author}

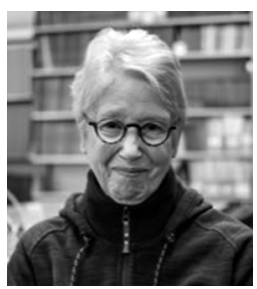

Sharon Dunwoody is Evjue-Bascom Professor of Journalism and Mass Communication Emerita at the University of Wisconsin-Madison. A Science Journalist in her early years, she studied science journalism in her PhD work at Indiana University and has spent most of her academic career teaching science communication skills and studying the creation and impact of mediated science stories. She has published many journal articles and has authored or coedited several books about science journalism. 